\title{
Trends of Transfusion Transmissible Infections Among Blood Donors by Chemiluminescent Assay in a Tertiary Care Centre
}

\author{
V Sandhya Krupal ${ }^{1}$, I.V. Renuka ${ }^{2 *}$, Chitturi Ramya ${ }^{2}$ and R. Vaishnavi ${ }^{2}$ \\ 'Pathology Department, RI medical college, Chinnakakani, Guntur DT, AP, India \\ ${ }^{2}$ Pathology Department,NRI medical college, Chinnakakani, Guntur DT,AP, India
}

\section{ABSTRACT}

Background: Blood transfusion is an important,integral and life saving procedure but simultaneously, carries risk of transmitting Transfusion Transmissible Infections(TTIs). The present study was done to find out the seroprevalence and changing trends of various TTIs among blood donors.

Methods: Blood donors who attended our blood bank during May 2014 to May 2019 and fulfilled uniform guidelines approved by National blood transfusion council were included. Data regarding type of donors, sex and screening test results were collected from the records.

Result: Out of 32046 donors, voluntarydonors(76.3\%) were more in comparison to replacement donors(23.7\%) and out of 32046, $31944(99.7 \%)$ were males and 102(0.3\%) were females.Amongst TTIs, seroprevalence of HBV(1.3\%) was highest in the blood donors followed by $\mathrm{HCV}(0.65 \%)$, HIV $(0.29 \%)$,Syphilis $(0.06 \%)$ and Malaria $(0.006 \%)$. TTIs were more seroprevalent in replacement donors than voluntary donors.

Conclusion: TTIs were more in replacement donors than voluntary donors. A decreasing trend in the seropositivity percentage of most of the TTIs was seen due to strict donor selection criteria and counselling of blood donors. Stringent screening, implementation of more sensitive tests like Nucleic acid amplification test/Chemiluminescent assay and public awareness programs are needed to improve the prevention of TTIs.

Keywords: Transfusion Transmissible Infections,Seroprevalence,Voluntarydonors,Replacementdonors, Chemiluminescent Assay.

\section{Introduction}

Blood transfusion is an important, integral and life saving procedure. Blood banks main function is to provide safe, sufficient and timely supply of blood and blood components to those in need while carrying out this function, the Blood bank should ensure the act of blood donation is safe and causes no harm to the donor. Blood bank should maintain a pool of safe, voluntary non-remunerated blood donors, replacement donors and take necessary steps to ensure products obtained from donated blood are efficacious for the recipient and carries minimal risk of any transfusion transmissible infections ${ }^{[1,2,3]}$.

Transfusion transmissible infections(TTIs) are mainly caused by Human immunodeficiency virus(HIV), Hepatitis $\mathrm{B}$ virus[HBV], Hepatitis c virus[HCV], Treponema pallidum and Malaria parasite. It is important to know the prevalence of TTIs in the general population and blood donors for continuous monitoring and reduce the risk of $\mathrm{TTIS}^{[2]}$. In spite of improved donor screening, certain factors as window, period, concealed medical history and asymptomatic carriers impact a serious challenge for blood safety ${ }^{[3]}$. The present study aims at finding out the incidence of TTIs and their changing trends using sensitive techniques like chemiluminescent assay as it is precise, reliable and gives faster turn around time(TAT).

\section{Materials and Methods}

The present study was carried out our Blood bank after obtaining Institute Ethical Committee clearance. The present study included all the blood donors(voluntary and replacement) who fulfilled uniform guidelines approved by National blood transfusion council at our blood bank, during the period May 2014 to May 2019, a period of 5 years. Vital signs and weight recorded. Donors who donated blood repeatedly were counted as once. All the data was collected from the records. Donors who didn't meet the blood donor criteria were excluded.

Donor's venous blood was collected as per norms. Following proper sterilization and precautions, collected blood units were stored in appropriate conditions. Serum was separated by centrifugation at a speed of $3500 \mathrm{rpm}$ for 5 minutes. Each blood donor's blood group was determined. Each donor was tested for anti-HIV1\&2, HBs antigen(Ag) and anti -HCV by enhanced chemiluminescent immunotechique (Ortho-Clinical Diagnostic-VitrosBuckinghamshire, 
United Kingdom). Malaria screening was done using the rapid immuno-chromatographic technique (Alere Medical Pvt Ltd, Daharuhera, Haryana, India) and Syphilis was screened using Rapid Plasma Reagin(RPR) assay(Labcare Diagnostic GurugoanHaryana, India). The tests were validated as per the manufacturer's protocol.

\section{Result}

A total of 32046 were screened for TTIs during the study period; of these $31944(99.7 \%)$ were males and 102(0.3\%) were females. Voluntary blood donors were 24429 (76.3\%) and 7617(23.7\%) were replacement donors (Table 1). Voluntary blood donor's percentage increased in May 2017 to May 2019(92.7\%) in comparison to April 2014 to May 2017(64.9\%). Seroprevalence of TTIs were higher among replacement donors than voluntary donors (Table 2). This difference was statistically significant.
Out of 770 positive TTIs ,95(0.29\%) were seropositive for anti-HIV antibodies,442(1.3\%) were found to be carriers of HBV (HBsAg),211(0.65\%) were seropositive for anti-HCV antibodies, 22(0.06\%) were seropositive for Syphilis and 2(0.006\%) were seropositive for Malaria. Highest number of donors were seropositive for $\mathrm{HBsAg}$ followed by HCV, HIV, Syphilis and least number were seropositive for Malaria. On year wise analysis, the seropositivity percentage of TTIs a decrease trend seen except in HCV(Figure 1) . During the study period May 2015 to April 2016 highest number of TTIs seroprevalence was seen among replacement donors (Table 4). HIV, HBV, $\mathrm{HCV}$, Syphilis and Malaria were more prevalent among males and all the females were negative for TTIs. Highest seroprevalence of TTIs was seen among the age group 2130 years, followed by the age group 31-40 years and lowest was observed within the age group of $<20$ years(Table 5).

Table 1: Year wise study blood donors.

\begin{tabular}{|c|c|c|c|c|c|}
\hline \multirow{2}{*}{ Year } & \multicolumn{2}{|r|}{ Voluntary } & \multicolumn{2}{|c|}{ Replacement } & \multirow{2}{*}{ Total } \\
\hline & Male & Female & Male & Female & \\
\hline May 2014-April 2015 & $3112(54.5 \%)$ & $2(0.03 \%)$ & $2586(45.33 \%)$ & $8(0.14 \%)$ & 5708 \\
\hline May 2015-April 2016 & $4817(70.36 \%)$ & $3(0.04 \%)$ & $2023(29.56 \%)$ & $3(0.04 \%)$ & 6846 \\
\hline May 2016-April 2017 & $4457(68.3 \%)$ & $9(0.13 \%)$ & $2044(31.3 \%)$ & $18(0.27 \%)$ & 6528 \\
\hline May 2017-April 2018 & $5439(89.8 \%)$ & $19(0.3 \%)$ & $591(9.8 \%)$ & $7(0.1 \%)$ & 6056 \\
\hline May 2018-April 2019 & $6538(94.6 \%)$ & $33(0.55 \%)$ & $337(4.9 \%)$ & 0 & 6908 \\
\hline Total & $24363(76 \%)$ & $66(0.2 \%)$ & $7581(23.7 \%)$ & $36(0.1 \%)$ & 32046 \\
\hline
\end{tabular}

Table 2: Seroprevalence of TTIs among blood donors.

\begin{tabular}{|l|r|r|r|r|}
\hline & TTIs Positive & TTIs Negative & Total & 24429 \\
\hline Voluntary blood donor & 508 & 23921 & 7353 & P value=0.0001 \\
\hline Replacement blood donor & 264 & 7617 & . \\
\hline
\end{tabular}

Table 3: TTIs seroprevalence among study population year wise.

\begin{tabular}{|l|r|r|r|r|r|r|}
\hline TTIs & May 2014-April & May 2015-April & May 2016-April & May 2017-April & May 2018 -May & Total \\
\hline HIV(anti-HIV1\&2) & $35(0.6 \%)$ & $22(0.3 \%)$ & $18(0.2 \%)$ & $14(0.2 \%)$ & $6(0.08 \%)$ & $95(0.29 \%)$ \\
\hline HBV(HBsAg) & $103(1.8 \%)$ & $89(1.3 \%)$ & $96(1.4 \%)$ & $80(1.3 \%)$ & $74(1.07 \%)$ & $442(1.3 \%)$ \\
\hline HCV(anti-HCV) & $55(0.96 \%)$ & $36(0.5 \%)$ & $49(0.7 \%)$ & $34(0.5 \%)$ & $37(0.6 \%)$ & $211(0.65 \%)$ \\
\hline Syphilis(RPR) & $14(0.2 \%)$ & $6(0.09 \%)$ & $1(0.01 \%)$ & 0 & $1(0.01 \%)$ & $22(0.06 \%)$ \\
\hline Malaria(Pan/Pf) & 0 & $1(0.01 \%)$ & $1(0.01 \%)$ & 0 & 0 & $2(0.006 \%)$ \\
\hline Total & $\mathbf{2 0 7}$ & $\mathbf{1 5 4}$ & $\mathbf{1 6 5}$ & $\mathbf{1 2 8}$ & $\mathbf{1 1 8}$ & $\mathbf{7 7 2}$ \\
\hline
\end{tabular}

Table 4: Distribution of seropositive cases in Voluntary donors(VD) and Replacement donors(RD).

\begin{tabular}{|l|l|l|l|l|l|l|l|l|l|l|}
\hline \multirow{2}{*}{ Year } & \multicolumn{3}{|c|}{ HIV HBV } & \multicolumn{3}{c|}{ HCV } & \multicolumn{2}{c|}{ Syphilis } & \multicolumn{2}{c|}{ Malaria } \\
\cline { 2 - 12 } & VD & RD & VD & RD & VD & RD & VD & RD & VD & RD \\
\hline May 2014-April 2015 & 25 & 10 & 58 & 45 & 29 & 26 & 11 & 3 & 0 & 0 \\
\hline May 2015-April 2016 & 9 & 13 & 36 & 53 & 16 & 20 & 2 & 4 & 0 & 1 \\
\hline May 2016-April 2017 & 7 & 11 & 67 & 29 & 25 & 24 & 1 & 0 & 0 & 1 \\
\hline May 2017-April 2018 & 10 & 4 & 74 & 6 & 26 & 8 & 0 & 0 & 0 & 0 \\
\hline May 2018-May 2019 & 5 & 1 & 71 & 3 & 35 & 2 & 1 & 0 & 0 & 0 \\
\hline
\end{tabular}


Table 5: Age wise distribution of TTIs.

\begin{tabular}{|l|r|r|r|r|r|r|}
\hline Age & HIV & HBV & HCV & Syphilis & Malaria & Total \\
\hline $18-20$ years & 0 & 2 & 0 & 1 & 0 & 3 \\
\hline $21-30$ years & 31 & 135 & 59 & 9 & 0 & 234 \\
\hline $31-40$ years & 33 & 129 & 56 & 6 & 1 & 225 \\
\hline $41-50$ years & 29 & 90 & 49 & 5 & 1 & 174 \\
\hline $51-60$ years & 2 & 86 & 47 & 1 & 0 & 136 \\
\hline
\end{tabular}

Table:6 Comparison study.

\begin{tabular}{|c|c|c|c|c|c|c|}
\hline & Present study & $\begin{array}{r}\text { Sundaramurthy } \\
\text { et al., }{ }^{11} 2017\end{array}$ & $\begin{array}{r}\text { Meena S et al., } \\
{ }^{\left[{ }^{[8} 2018\right.}\end{array}$ & $\begin{array}{r}\text { Kumar A et al., } \\
{ }^{[9]} 2014\end{array}$ & $\begin{array}{r}\text { GiriPA et al., } \\
{ }^{[6]} 2012\end{array}$ & $\begin{array}{r}\text { Garg et al., } \\
{[10] 2001}\end{array}$ \\
\hline HBV & $1.3 \%$ & $0.42 \%$ & $2.14 \%$ & $1.76 \%$ & $1.09 \%$ & $3.4 \%$ \\
\hline $\mathrm{HCV}$ & $0.65 \%$ & $0.56 \%$ & $0.66 \%$ & $0.20 \%$ & $0.74 \%$ & $0.28 \%$ \\
\hline HIV & $0.29 \%$ & $0.13 \%$ & $0.60 \%$ & $0.53 \%$ & $0.07 \%$ & $0.44 \%$ \\
\hline Syphilis & $0.06 \%$ & Nil & $0.05 \%$ & $0.07 \%$ & $0.07 \%$ & $0.22 \%$ \\
\hline Malaria & $0.006 \%$ & $0.01 \%$ & $0.14 \%$ & Nil & Nil & Nil \\
\hline
\end{tabular}

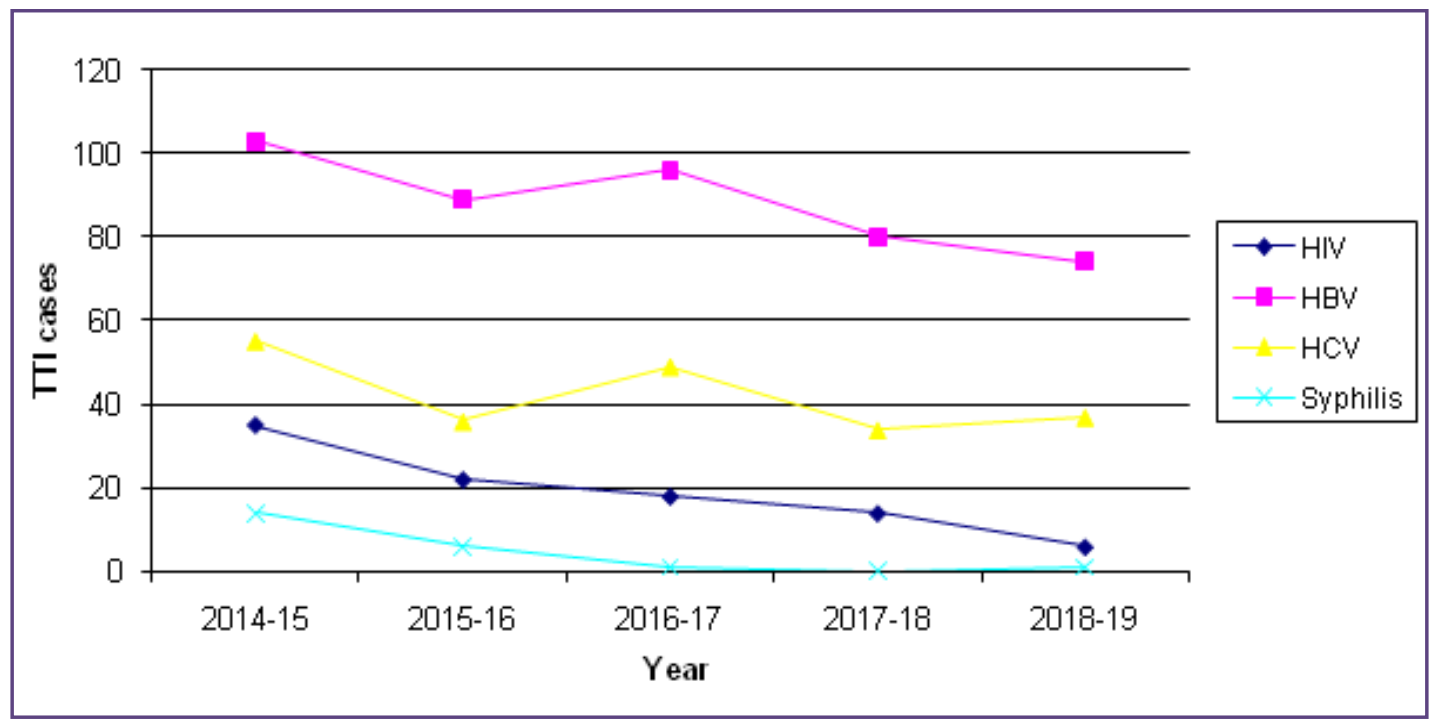

Fig. 1:Year wise analysis of TTIs.

\section{Discussion}

Blood transfusion is most important, integral and life saving procedure, but carries risk of transmitting TTIs. TTIs poses a major threat in developing countries. Screening of blood ensures safe blood and blood products, but gives incidence of TTIs among the study population. The seroprevalence rate of TTIs reported among the blood donors in India is: $0.084 \%-3.87 \%, 0.24-12 \%, 0.0001-1.5 \%, 0.001 \%$ - $0.57 \%, 0.0085-3 \%$ for HIV, HBV, HCV, Malaria and Syphilis respectively ${ }^{[4,5]}$.

In present study voluntary donors were more predominant being $76.3 \%(24429 / 32046)$ in comparison to replacement donors being 23.7\% (7617/32046). The percentage of voluntary donors has increased to $92.7 \%$ during May 2017 to May 2019 in comparison to 64.9\% during April 2017 to May 2014 due to general public awareness and our motivation(Table 1).

The study population included in the present study belongs to a diverse group so no specific risk factor could be isolated. Chemiluminescent assay was used as screening assay for detecting HIV,HBV and HCV. Rapid immunochromatographic technique for detecting Malaria and RPR for Syphilis.

TTIs were more prevalent in males and was in concordance with Giri PA et al. ${ }^{[6]}$. And highest prevalence of TTIs was 
seen among the age group 21-30 years, followed by the age group 31-40 years and lowest was observed within the age group of $<20$ years(Table 5 ).

In the present study, TTIs seroprevalence was $2.4 \%$ (772/32046). TTIs seroprevalence in voluntary donors was $2.07 \%$ (508/24429) when compared with 3.46\% (264/7617) in replacement donors. The percentage of TTIs was highest in replacement donors during study period May 2015 to April 2016(Table 4).This correlation was statistically significant : the $p$ value was 0.0001 (Table2). This is similar to other studies done in India by Pahuja et al..$^{[7]}$ and Meena $\mathrm{S}$ et al. ${ }^{[8]}$.On year wise analysis, the percentage of all TTIs a decrease trend seen ,as highest TTIs percentage was reported during May 2014 to April 2015 and least TTIs percentage was reported during May 2018 to May 2019.

The highest prevalence of TTIs in the present study was HBV being $1.3 \%$ which is in concordance with Bhattacharya $P$ et al., ${ }^{[10]}$ who also reported the percentage of HBV was $1.66 \%$.Percentage of $0.69 \%, 1.67 \%, 1.7 \%{ }^{[11,12,13]}$ have been reported by various studies from different parts of India.

Next highest prevalence of TTIs cases in the present study was $\mathrm{HCV}$, being $0.6 \%$ which was in concordance with Suresh B et al., ${ }^{[12]}$ who also reported the percentage of HCV was $0.56 \%$.Various studies from western, southern India and northern states reported $\mathrm{HCV}$ percentage to be $0.35 \%{ }^{[10]}, 0.01 \% \%^{[11]}, 0.29 \% \%^{[14]}$ respectively. $\mathrm{HCV}$ seropositivity was high in our studies compared to other studies may be due highly sensitive CLIA screening and increased carrier state in the study population posing to global health threat.

The third highest prevalence of TTIs in the present study was HIV being $0.29 \%$ which is in concordance with Garg $\mathrm{S}$ et al., ${ }^{[10]}$ who also reported the percentage of HIV was $0.47 \%$. Seroprevalence of $3.8 \%$ and $11.7 \%{ }^{[15,16]}$ have been reported by various studies. A decreasing trend in seroprevalence of HIV was observed in present study due to improved awareness among study population.

The fourth highest seroprevalence of TTIs in the present study was Syphilis being $0.06 \%$ which was in concordance with Meena $\mathrm{S}$ et al., ${ }^{[8]}$.Other studies documented Syphilis prevalence as $0.08 \%$ and $0.90 \%{ }^{[16,17]}$. Seroprevalence of malaria was least being $0.006 \%$ was low in comparison studies done by Sundaramurthy et al., ${ }^{[3]}$ and Meena $\mathrm{S}$ et al., ${ }^{[8]}$.

\section{Conclusion}

TTIs were more prevalent in replacement donors than voluntary donors. Hence a greater number of voluntary donors should be encouraged. Out of all TTIs, seroprevalence of HBV (1.3\%) was highest in the donors followed by $\mathrm{HCV}(0.65 \%)$,HIV $(0.29 \%)$,Syphilis $(0.06 \%)$ and Malaria $(0.006 \%)$. HCV seroprevalence was high in our studies compared to other studies and may be due highly sensitive Chemiluminescent assay screening and strict donor selection criteria.

\section{Acknowledgements}

Nil

\section{Funding}

Nil

\section{Competing Interests}

Nil

\section{Reference}

1. Saran R K. Transfusion Medicine Technical Manual. Directorate General of Health Services. Ministry of Health and Family Welfare. Government of India.2003.

2. Accreditation Standards on Blood Bank/Blood Centers and Transfusion Services. National Accreditation for Hospitals and HealthCare Providers. Quality Council of India. Third Edition.2016.

3. Sundaramurthy et al. Seroprevalence of transfusion transmissible infections among blood donors by chemiluminescent assay in tertiary care centre. J Infect DevCtries 2018;12(1):031-036.

4. Irshad M, Peter S. Spectrum of Viral hepatitis in thalassemic children receiving multiple blood transfusions. Indian J Gastroenterol .2002;21:183-184.

5. Chattoraj A, Behl R, Kataria V. Infectious disease markers in blood donors. Med J Armed Forces India.2008; 64:33-35.

6. Giri PA, Deshpande JD, Phalke DB, Karle LB. Seroprevalence of transfusion transmissible infections among voluntary blood donors at a tertiary care teaching hospital in rural area of India. J Fam Med Prim Care.2012; 1:48-51.

7. Pahuja S, Sharma M, Baitha B, Jain M. Prevalence and trends of markers of hepatitis $\mathrm{C}$, hepatitis $\mathrm{B}$ virus and human immunodeficiency virus in Delhi blood donors: a hospital based study. Jpn J Infect Dis.2007 Nov;60(6):389-91.

8. Meena S. Maheshwari V, Gupta D. Seroprevalence and trends of transfusion transmissible infections among voluntary and replacement donors-an institutional retrospective study. Trop J Path Micro. 2018;4(4):330-335.

9. Kumar A, Sharma SM, Ingole NS, Gangane N. Seroprevalence of Transfusion transmissible infections (TTIs) among blood donors in a tertiary care hospital, central India: A prospective study. Muller J Med Sci Res 2014;5:113-116.

10. Garg S, Mathur DR, Garg DK(2001). Comparison of seropositivity of HIV, HBV, HCV and syphilis in replacement and voluntary blood donors in western India. Indian J Pathol Microbiol 44: 409-412. 
11. Bhattacharya $\mathrm{P}$, Chandra $\mathrm{PK}$, Datta $\mathrm{S}$, Banarjee A, Chakraborthy S, Rajendran K Significant increase in HBV, HCV, HIV and Syphilis infections among blood donors in West Bengal, Eastern India 2004-2005:exploratory screening reveals high frequency of occult HBV infection. World J Gastroenterol 13:3730-3733.

12. Fatima A, Begum F, Kumar K (2016). Seroprevalence on transfusion transmissible infections among blood donors in Nizamabad district of Telangana State. A six years study .IAIM 3:73-78.

13. Suresh B, Sreedhar Babu K V, Venkataramana B V, Chandra Mouli P (2016).Burden of transfusion transmissible viral infections among blood donors at a tertiary care referral teaching hospital in South India.J Clin Sci Res 5:160-163.

14. Arora D, Arora B, Khetarpal A (2010). Seroprevalence of HIV,HBV,HCV and Syphilis in blood donors in Southern Haryana.Indian J Pathol Microbiol 53:308.
15. Mandal R, Mondal K .Transfusion transmissible infections among blood donors from a sub -Himalayan rural tertiary care centre in Darjeeling ,India.J Tradit Complement Med 2016; 6:224-229.

16. Dobariya GH, Raja K, Unagar C, Pandya A, Patel J, Jarag M, Wadhwani SJ (2016). Prevalence and trends of transfusion transmitted infections among blood donors of blood banks attached to government hospital of south Gujarat ,India.Int J Res Med Sci 4:4123-4127.

17. Bhawani Y, Rao PR, Sudhakar V. Seroprevalence of transfusion transmissible infections among blood donors in a tertiary care hospital of Andhra Pradesh from. 2004-2009. Biology and Medicine 2010;2 (4):45-48.

18. Jasani J, Patel V, Bhuva K, Vachhani A, Patel H, Falleiro JJ. Seroprevalence of transfusion transmissible infections among blood donors in a tertiary care hospital.Int J Biol Med Res.2012;3(1):1423-1425.

*Corresponding author:

Dr. I.V.Renuka, Professor and Head of department, Pathology Dept, NRI medical college, Chinnakakani,Guntur Dt, Andhra Pradesh,India 522503

Phone: +91 9848134166

Email: repriya56@gmail.com

Financial or other Competing Interests: None. 